\title{
Proacrosin as a marker of meiotic and post-meiotic germ cell differentiation: quantitative assessment of human spermatogenesis with a monoclonal antibody
}

\author{
D. Bermúdez ${ }^{1}$, D. Escalier ${ }^{2}$, J. M. Gallo ${ }^{3 *}$, A. Viellefond ${ }^{4}$, \\ F. Ríus ${ }^{5}$, I. Pérez de $\operatorname{Vargas}^{1}$ and J. Schrével ${ }^{3}$ \\ ${ }^{1}$ Departamento de Morfología Normal y Patológica, Facultad de Medicina, Universidad de \\ Málaga, 29080 Málaga, Spain; ${ }^{2}$ Laboratoire de Biologie de la Reproduction et du \\ Développement, CHU Bicêtre, 78 rue du Général Leclerc, 94275 Le Kremlin Bicêtre, France; \\ ${ }^{3}$ Museum National d'Histoire Naturelle, 61 Rue Buffon, 75231 Paris Cedex 05 and URA \\ CNRS 290, France; ${ }^{4}$ Laboratoire d'Anatomo-Pathologie, CHU Bicêtre, 78 Rue du Général \\ Leclerc, 94275 Le Kremlin Bicêtre, France; and ${ }^{5}$ Cátedra de Bioestadistica, Facultad de Medicina, \\ Universidad de Málaga, 29080 Málaga, Spain
}

\begin{abstract}
A quantitative immunohistochemical study of human spermatogenesis was performed using the 4D4 anti-proacrosin monoclonal antibody (mAb 4D4) as a marker of meiotic and post-meiotic germ cell differentiation. Cells from 15 testicular biopsies with normal spermatogenesis, 18 with slight and nine with marked hypospermatogenesis and six with maturation arrest were assigned to spermatogenic stages according to both nuclear maturation and proacrosin labelling patterns. The results showed that four spermatogenesis steps (mid- and late-pachytene primary spermatocytes, early and late spermatids) have to be separately considered for the classification of a given biopsy. Conversely, data from primary spermatocytes in the metaphase, anaphase and telophase stages and secondary spermatocytes did not show significant differences between biopsies. We conclude that: (1) slight hypospermatogenesis is due only to fewer cells entering meiosis, whereas in marked hypospermatogenesis there is also germ cell loss during the later meiotic steps and spermiogenesis; (2) the sloughing of germ cells from the epithelium could be of pathological significance; and (3) immunodetection with $\mathrm{mAb} 4 \mathrm{D} 4$ improves the assessment of spermatogenesis because it can label a protein expressed as early as meiotic prophase. In addition, mAb $4 \mathrm{D} 4$ labels a protein which is a marker of the Golgi complex allowing the detection of disturbances of cytoplasmic events during meiosis or spermiogenesis. Such an analysis is facilitated by mAb 4D4 labelling of paraffin-embedded sections.
\end{abstract}

\section{Introduction}

A quantitative analysis of the germinal epithelium allows the precise localization of the spermatogenic stage of a disorder and can distinguish maturation arrest from some hypospermatogenesis (Narbaitz et al., 1978; Sigg and Hedinger, 1981). Spermatogenesis has been quantified by means of classical cytological stains to determine stage of nuclear maturation (Rowley and Heller, 1971; Skakkebaek et al., 1973; Weissbach and Ibach, 1976; Zukerman et al., 1978; Johnson et al., 1987; Paniagua et al., 1987; Hirsch and Choi, 1990).

Human spermatogenesis has been analysed by means of probes recognizing germ cell components, such as lectinbinding sites or acrosomal antigens (Flörke-Gerloff et al., 1983;

*Present address: Department of Neurology, Institute of Psychiatry, De Crespigny Park, London SE5 8AF, UK.

Revised manuscript received 6 July 1993.
Phi-Van et al., 1983; Jassim and Festenstein, 1987; Jones et al., 1988; Kurpitz et al., 1988; Wollina et al., 1989; Herr et al., 1990; Kurth et al., 1991). The monoclonal antibody mAb 4D4 is specific to the $50-55 \mathrm{kDa}$ primate proacrosin sequestered in the matrix of the anterior region of the acrosome (Gallo et al., 1991) and paraffin embedded sections can be labelled with the 4D4 monoclonal anti-proacrosin antibody (Gallo et al., 1991). Moreover, specific labelling patterns of $\mathrm{mAb} 4 \mathrm{D} 4$ are found at various stages of spermatogenesis from mid-pachytene stage onwards. Identification of germ cell type is therefore possible and cytoplasmic processes of spermatogenesis can be observed because proacrosin labelling during meiosis is a marker of Golgi complex partitioning (Escalier et al., 1991). This new immunohistochemical approach has allowed meiotic arrests due to intra-nuclear disturbances to be distinguished from those resulting from cytoplasmic event impairment (Escalier et al., 1992). 
Table 1. Comparison of semen characteristics of patients with rate of spermatogenesis

\begin{tabular}{|c|c|c|c|c|c|c|}
\hline \multicolumn{6}{|c|}{ Semen characteristics } & \multirow[b]{2}{*}{$\begin{array}{l}\text { Spermatogenesis } \\
\text { (number of men) }\end{array}$} \\
\hline $\begin{array}{l}\text { Number of } \\
\text { spermatozoa } \mathrm{ml}^{-1}\end{array}$ & $\begin{array}{l}\text { Volume } \\
\text { (ml) }\end{array}$ & $\mathrm{pH}$ & $\begin{array}{c}\text { Vitality } \\
(\%)\end{array}$ & $\begin{array}{l}\text { Motility } \\
(\%)\end{array}$ & $\begin{array}{c}\text { Normal spermatozoa } \\
(\%)\end{array}$ & \\
\hline$>20$ & $1,7-5$ & $7,4-8,4$ & $48-87$ & $15-70$ & $11-68$ & NS (5) \\
\hline \multirow[t]{3}{*}{$<20$} & $1,4-6,2$ & $6,8-7,2$ & $6-93$ & $0-40$ & $0-46$ & $\mathrm{SH}(2)$ \\
\hline & & & & & & $\mathrm{MH}(4)$ \\
\hline & & & & & & $\mathrm{MA}(1)$ \\
\hline \multirow[t]{4}{*}{0} & $2,5-6,4$ & $7,2-8,1$ & & & & NS $(4)^{a}$ \\
\hline & & & & & & $\mathrm{SH}(4)^{\mathrm{a}}$ \\
\hline & & & & & & $\mathrm{MH}(1)^{\mathrm{a}}$ \\
\hline & & & & & & $\mathrm{MA}(2)^{\mathrm{b}}$ \\
\hline
\end{tabular}

NS: normal spermatogenesis; SH: slight spermatogenesis; $\mathrm{MH}$ : marked hypospermatogenesis; MA: maturation arrest; ${ }^{\mathrm{a}}$ genital tract obstruction; 'secretory azoospermia.

In the present study, quantitative analysis of 55 testicular biopsies including controls and examples with different levels of impaired spermatogenesis was performed using mAb 4D4. Testis specimens were from necropsies and from infertile patients with either excretory obstruction or secretory disorders. Six spermatogenesis steps have been recorded as early as the prophase I step, including germ cells present in the tubular lumen. The aim of this study was to quantify stages in human spermatogenesis more clearly in normal and pathological conditions by means of this precise marker and to compare the classification of spermatogenesis impairment by mAb 4D4 with that normally obtained from nuclear cytology.

\section{Materials and Methods}

\section{Patients and tissues}

The present study was performed on 55 testicular biopsies, 47 were from 31 infertile patients and eight were from five fertile men who died in traffic accidents or from causes not related to testicular or endocrine diseases. Samples were obtained after ethical approval and with the consent of patients. The average age was 34 (range 25-48). Testicular biopsies of patients were obtained by surgical procedures under general anaesthesia, whereas autopsies were carried out between 3 and $5 \mathrm{~h}$ after death. The biopsies were bilateral in 19 men and unilateral in 17 men. The semen characteristics of the patients are presented in Table 1. Semen samples were obtained after 3-5 days abstinence. Sperm characteristics were unknown for 11 testis biopsies, eight from five necropsies and three from two infertile patients. Seven testis biopsies exhibiting only Sertoli cell syndrome were excluded from the quantitative evaluation of the results.

\section{Biopsy processing and immunohistochemistry}

Small fragments $(4 \mathrm{~mm} \times 2 \mathrm{~mm}$ ) of each testicular specimen were fixed in Bouin's solution, embedded in paraffin wax and sectioned at $3 \mu \mathrm{m}$. Immunohistochemistry was performed as described using the three-step immunoperoxidase technique with biotin-avidin (Vector Laboratories, Burlingame, CA) (Escalier et al., 1991). The sections were preincubated with PBS-5\% BSA (grade V, Sigma, St Louis, MO), and then exposed for $\mathrm{Ih}$ to $\mathrm{mAb} 4 \mathrm{D} 4$ ascite fluid (bio Merieux, Marcy-L'Etoile) diluted 1:1200 in PBS-5\% BSA. As specificity of $\mathrm{mAb} 4 \mathrm{D} 4$ for testicular proacrosin has been demonstrated by western blotting (Escalier et al., 1991), the specificity of the labelling of each testicular biopsy was checked by substituting $\mathrm{mAb}$ 4D4 with PBS-5\% BSA. Unlabelled testis biopsies exhibiting Sertoli cell syndrome were also used as controls. The sections were counterstained with Harris' haematoxylin and mounted in an aqueous medium (Glycergel, Dakopatts, Santa Barbara, CA).

The slices were observed under an Olympus $\mathrm{BH}-2$ photomicroscope. Cell quantification was performed at a magnification of $\times 400$. Photomicrographs were taken at $\times 630$ using Agfa Ultra 50 films and automatic exposure.

\section{Cell identification criteria}

$\mathrm{MAb} 4 \mathrm{D} 4$ labelling is observed as early as the midpachytene step in humans (Escalier et al., 1991). The cell maturation steps were identified taking into account both nuclear features (Clermont, 1963; Holstein and Roosen-Runge, 1981; Schultze and Rehder, 1984) and the cellular location and pattern of mAb 4D4 labelling (Escalier et al., 1991). Briefly, the 4D4 labelling patterns were: (1) in mid-pachytene primary spermatocytes a single 4D4 labelled body about $3 \mu \mathrm{m}$ in length; (2) in late-pachytene primary spermatocytes two distinct 4D4 labelled bodies, either close to each other or at various distances from each other; (3) in metaphasic, anaphasic and telophasic primary spermatocytes partitioning of the 4D4 labelled bodies into a pattern related to the chromosome movement; and (4) in secondary spermatocytes, two 4D4 labelled bodies. Spermatids were classified in agreement with the criteria of Clermont (1963), Escalier et al. (1991) and Rowley and Heller (1971): Sa spermatids contain a spherical nucleus and a single round 4D4 labelled body; in Sb spermatids, the nucleus is beginning to lose its spherical shape and is becoming slightly elongated; the 4D4 labelled body is more or 
less flattened on the side facing the nucleus; Sc spermatids have a strongly elongated nucleus and a crescent-shaped $4 \mathrm{D} 4$ labelled cap; and in Sd spermatids the chromatin has undergone further condensation; the nucleus is reduced in width and anteriorly tapered, as for 4D4 acrosomal labelling. Degenerating germ cells were identified by both dense masses of karyoplasm and unspecific labelling of the whole cytoplasm.

\section{Measurement of spermatogenesis}

The distance between cuts was about $30 \mu \mathrm{m}$ (every tenth section) to prevent double counting of the cells. Eighteen sections of each testis biopsy were immunolabelled. Determination of the number of germ cells was performed on 25 strictly round cross-sectioned seminiferous tubules for each testis biopsy. Tubules near the biopsy edge were excluded to avoid a pressure artefact. All observations were made by the same individual without any knowledge of the clinical and seminal data of the patients.

The numbers of germ cells at the six following spermatogenic steps were determined in the seminiferous epithelium and in the tubular lumen: (1) mid-pachytene primary spermatocytes; (2) late-pachytene primary spermatocytes; (3) primary spermatocytes at metaphase, anaphase and telophase stages; (4) secondary spermatocytes; (5) early spermatids (including Sa plus $\mathrm{Sb}$ spermatids); and (6) late spermatids (including Sc plus Sd spermatids). Moreover, at both the epithelial and luminal levels, the numbers of the following germ cells were also determined: (7) unlabelled late spermatids; (8) multinucleate germ cells; and (9) degenerating germ cells. In addition (10) unlabelled round germ cells and (11) Sertoli cells at the lumen level only were included for quantification. A total of 20 differential cell counts (nine in the seminiferous epithelium and 11 in the lumen) were performed in each of the 25 round cross-sectioned seminiferous tubules considered for each testicular biopsy.

Differential cell counts were expressed calculating the median with $95 \%$ confidence limits of each cell type recorded per seminiferous tubule cross-section. After classification of the testicular biopsies by their germ cell distribution (see statistical analysis section), the spermatogenic yield for each testicular biopsy group was expressed calculating the early spermatid:pachytene primary spermatocyte and late spermatid:early spermatid ratios.

\section{Statistical analysis}

The distribution of the germ cells at each maturation step and for each testicular biopsy was first controlled using a repeated measure Manova analysis (Winer, 1962).

Scaling unfolding (Young, 1987) and cluster analysis (Hand, 1981) were performed to distribute the testicular biopsies into the new quantitatively defined groups. Comparison of the values was performed by the Kruskal-Wallis test, because the normality or homocedasticity conditions or both conditions were violated.

The germ cell types showing a significant variation between groups were taken into account and a multivariant stepwise discriminant analysis (Hand, 1981) was performed to check whether the groups were effectively defined by the variables and to select the germ cell steps exhibiting a required level of discrimination to predict testicular biopsies attribution to a group with an overall accuracy of $97.92 \%$. Once a set of variables was found that provided satisfactory discrimination between groups, a set of classification functions was derived which permitted the classification of new samples. The changes in the statistical Wilk's lambda showed as the information in successive discriminant functions was removed.

The number of each cell type present in the seminiferous epithelium and in the lumen were compared by calculating the correlation coefficients within each testicular biopsy group.

\section{Results}

Seven of the 55 testicular biopsies studied (four men, $11 \%$ ) were unlabelled by mAb $4 \mathrm{D} 4$ owing to maturation arrest of spermatogenesis before the mid-pachytene primary spermatocyte stage. This result was confirmed by conventional microscopy, ensuring that failure of labelling was not due to processing of testis sections. When labelled by mAb $4 \mathrm{D} 4(48$ testicular biopsies from $32 \mathrm{men}$ ), the biopsies showed a normal proacrosin reaction as seen by the step-specific $4 \mathrm{D} 4$ labelling patterns (Fig. 1). The immunostaining controls were negative.

\section{Classification of testicular biopsies}

From the scaling unfolding and cluster analysis data, the series of 48 testicular biopsies were separated into four groups (Table 2 and Fig. 2). The testicular biopsy groups were defined by the mean number of spermatids per seminiferous tubule cross-section (Table 2) according to Nistal and Paniagua (1984) and Nistal et al. (1987).

Normal spermatogenesis. In this group (group 1; $n=15$ biopsies) there were $32.36(30.60-33.84)$ early spermatids and $26.12(24.68-29.68)$ late spermatids per seminiferous tubule cross-section. By contrast, the number of mid- and latepachytene primary spermatocytes varied (5.96 (3.24-7.40) and 2.27 (1.32-2.98), respectively) (Fig. 2a). The early spermatid:pachytene primary spermatocyte ratio was about 3.93 and the late:early spermatid ratio about 0.83 .

Slight hypospermatogenesis. In comparison with group 1, the medians of mid-pachytene primary spermatocytes in this group (group 2, n=18 biopsies) and the number of early and late spermatids were $20 \%, 23 \%$, and $33 \%$ lower, respectively (Fig. $2 b$ ). Compared with group 1 , the early spermatid:pachytene primary spermatocyte ratio was unchanged (3.97) and the late:early spermatid ratio was lower $(0.70)$.

Marked hypospermatogenesis. This group (group $3 ; n=9$ biopsies) was characterized by the presence of $6.92(3.76-8.96)$ late spermatids per seminiferous tubule cross-section (Fig. 2c). The ratios of early spermatids:pachytene primary spermatocytes $(2.50)$ and late:early spermatids $(0.49)$ were much lower than those of Group 1. 


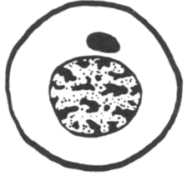

Mid-pachytene primary spermatocyte

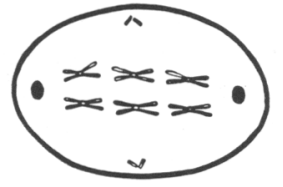

Metaphase primary spermatocyte

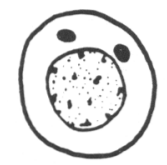

Secondary spermatocyte
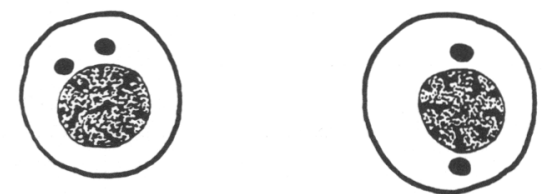

Late-pachytene primary spermatocytes

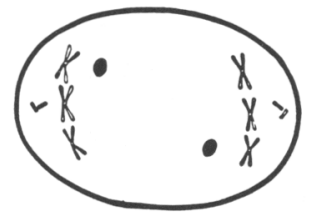

Anaphase

primary spermatocyte

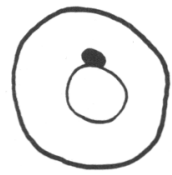

Spermatid Sa

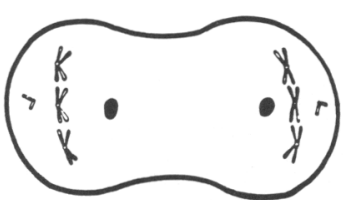

Telophase

primary spermatocyte

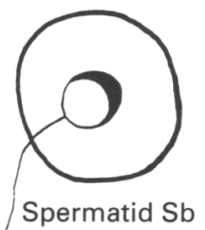

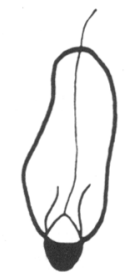

Spermatid Sc

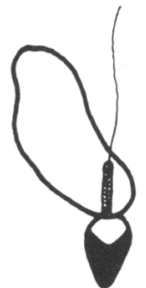

Spermatid Sd

Fig. 1. Diagram of the different stages of spermatogenesis according to both nuclear features and the cellular location and patterns of $\mathrm{mAb} 4 \mathrm{D} 4$ labelling.

Maturation arrest. In this group (group $4 ; n=6$ biopsies), there were few early spermatids $(2.40(0.00-3.04))$, late spermatids $(0.16(0.00-0.36))$ and late-pachytene primary spermatocytes $(0.70(0.00-1.04))$. In contrast, the medians of mid-pachytene primary spermatocytes $(6.48(4.68-8.60))$ were greater than those of groups 2 and $3(4.82(3.40-5.48)$ and 3.92 (1.84-4.04), respectively) (Fig. 2d).

\section{Discriminative spermatogenesis steps for classification of biopsies}

Two classes of germ cell could be distinguished by the median value per seminiferous tubule cross-section (as estimated by the Kruskal-Wallis test) (Table 2). The median for mid- and late-pachytene primary spermatocytes, and for early and late spermatids varied significantly from one testicular biopsy group to another, indicating that the germ cell steps concerned could be used for classification of biopsies. The median values for primary spermatocytes at metaphase, anaphase and telophase stages, and for secondary spermatocytes showed no significant variation from one group of biopsy to another, indicating that this factor could not be used to characterize impairment of spermatogenesis.
The median for unlabelled late spermatids varied significantly from one biopsy group to another. Compared with total late spermatids there were $14.41 \%, 14.79 \%, 25.75 \%$ and $33.33 \%$ in groups $1,2,3$ and 4 , respectively. Failure of $\mathrm{mAb}$ $4 \mathrm{D} 4$ labelling was very occasional for the other cell types, in all of the testicular biopsy groups. In addition, few degenerating germ cells were found in any group, although their median varied significantly from one biopsy group to another.

Stepwise discriminant analysis allowed the germ cell steps suitable for quantitative discrimination to be distinguished between groups with an overall accuracy of $97.92 \%$. The germ cell type arrangement according to decreased discriminating significance as expressed by Wilk's lambda values was (1) early spermatids (0.09), (2) late spermatids (0.05), (3) mid-pachytene primary spermatocytes $(0.04)$, (4) latepachytene primary spermatocytes $(0.03)$ and (5) unlabelled late spermatids $(0.02)$.

The accuracy of evaluation of spermatogenesis by this method led to about $50 \%$ discrepancy (Table 3) compared with evaluation by a pathologist using a conventional nonquantitative method according to diagnosis criteria of Colgan 
Table 2. Germ cells per seminiferous tubule cross-section in men

\begin{tabular}{|c|c|c|c|c|c|}
\hline \multirow[b]{4}{*}{ Number of biopsies } & \multicolumn{5}{|c|}{ Classification of spermatogenesis } \\
\hline & \multirow{3}{*}{$\begin{array}{c}\text { Normal } \\
15\end{array}$} & \multicolumn{2}{|c|}{ Hypospermatogenesis } & \multirow{3}{*}{$\begin{array}{c}\text { Maturation } \\
\text { arrest } \\
6\end{array}$} & \multirow{3}{*}{$P$} \\
\hline & & Slight & Marked & & \\
\hline & & 18 & 9 & & \\
\hline \multirow[t]{2}{*}{ Mid-pachytene } & $5.96^{\mathrm{a}}$ & $4.82^{\mathrm{a}, \mathrm{b}}$ & $3.92^{\mathrm{b}}$ & $6.48^{\mathrm{a}}$ & \multirow[t]{2}{*}{0.02} \\
\hline & $(3.24,7.40)$ & $(3.40,5.48)$ & $(1.84,4.04)$ & $(4.68,8.60)$ & \\
\hline \multirow[t]{2}{*}{ Late-pachytene } & $2.27^{\mathrm{a}}$ & $1.48^{\mathrm{a}}$ & $1.64^{\mathrm{a}}$ & $0.70^{\mathrm{b}}$ & \multirow[t]{2}{*}{0.04} \\
\hline & $(1.32,2.98)$ & $(1.04,1.76)$ & $(0.52,2.20)$ & $(0.00,1.04)$ & \\
\hline \multirow{2}{*}{ Metaphase, anaphase and telophase } & 0.20 & 0.12 & 0.12 & 0.08 & \multirow[t]{2}{*}{ NS } \\
\hline & $(0.00,0.28)$ & $(0.04,0.28)$ & $(0.00,0.24)$ & $(0.00,0.24)$ & \\
\hline \multirow[t]{2}{*}{ Secondary spermatocytes } & 0.28 & 0.36 & 0.52 & 0.12 & \multirow[t]{2}{*}{ NS } \\
\hline & $(0.20,0.36)$ & $(0.24,0.44)$ & $(0.12,1.00)$ & $(0.00,0.40)$ & \\
\hline \multirow[t]{2}{*}{ Early spermatids } & $32.36^{\mathrm{a}}$ & $25.01^{b}$ & $13.92^{c}$ & $2.40^{\mathrm{d}}$ & \multirow[t]{2}{*}{$<0.01$} \\
\hline & $(30.64,33.84)$ & $(22.48,27.04)$ & $(9.60,14.52)$ & $(0.00,3.04)$ & \\
\hline \multirow[t]{2}{*}{ Late spermatids } & $26.12^{\mathrm{a}}$ & $17.62^{b}$ & $6.92^{c}$ & $0.16^{\mathrm{d}}$ & \multirow[t]{2}{*}{$<0.01$} \\
\hline & $(24.68,29.68)$ & $(16.60,19.36)$ & $(3.76,8.96)$ & $(0.00,0.36)$ & \\
\hline \multirow[t]{2}{*}{ Unlabelled late spermatids } & $4.40^{\mathrm{a}}$ & $3.06^{b}$ & $2.40^{\mathrm{c}}$ & $0.08^{d}$ & \multirow[t]{2}{*}{$<0.01$} \\
\hline & $(3.84,4.76)$ & $(2.48,3.76)$ & $(1.04,3.64)$ & $(0.00,0.16)$ & \\
\hline \multirow[t]{2}{*}{ Multinucleate germ cells } & $0.44^{\mathrm{a}}$ & $0.42^{\mathrm{a}}$ & $0.28^{a}$ & $0.06^{\mathrm{b}}$ & \multirow[t]{2}{*}{0.02} \\
\hline & $(0.20,0.72)$ & $(0.24,0.56)$ & $(0.12,0.36)$ & $(0.00,0.12)$ & \\
\hline \multirow[t]{2}{*}{ Degenerating germ cells } & $1.24^{\mathrm{a}}$ & $0.96^{\mathrm{a}}$ & $0.60^{\mathrm{a}, \mathrm{b}}$ & $0.26^{\mathrm{b}}$ & \multirow[t]{2}{*}{0.04} \\
\hline & $(0.80,2.20)$ & $(0.72,1.04)$ & $(0.20,1.00)$ & $(0.04,0.36)$ & \\
\hline
\end{tabular}

Values are medians with $95 \%$ confidence limits. ${ }^{a, b, c, d}$ Values with different superscripts are significantly different $(P<0.05)$. NS: not significant.

Table 3. Comparison of the human testicular biopsies distribution obtained by the $4 \mathrm{D} 4$ method and the routine analysis ${ }^{a}$

\begin{tabular}{|c|c|c|c|}
\hline \multicolumn{2}{|c|}{ Quantitative analysis (4D4 method) } & \multicolumn{2}{|c|}{ Routine analysis } \\
\hline Group & Number of men & Group & Number of men \\
\hline Normal spermatogenesis & 15 & Normal spermatogenesis & 15 \\
\hline \multirow[t]{2}{*}{ Slight hypospermatogenesis } & 18 & Slight hypospermatogenesis & 3 \\
\hline & & Normal spermatogenesis & 15 \\
\hline \multirow[t]{2}{*}{ Marked hypospermatogenesis } & 9 & Slight hypospermatogenesis & 8 \\
\hline & & Normal spermatogenesis & 1 \\
\hline \multirow[t]{2}{*}{ Maturation arrest } & 6 & Marked hypospermatogenesis & 2 \\
\hline & & Maturation arrest & 4 \\
\hline
\end{tabular}

aCarried out according to the diagnosis criteria of Colgan et al, 1980, based on the histological appearance of the seminiferous epithelium.

et al. (1980). Testicular biopsies affected by either slight or marked hypospermatogenesis were frequently overestimated by routine analysis.

\section{Classification of testicular biopsies and semen characteristics}

Comparison between classification of testicular biopsies and semen characteristics could be made for only 26 men because the right and left testicular biopsies were classified in different groups in the six other patients. For three men, discrepancies between the two testicular biopsies were that there was normal spermatogenesis on one side and slight hypospermatogenesis on the other side. In the other three patients, the paired biopsies showed slight hypospermatogenesis and marked hypospermatogenesis. In five of these patients, the best quantitative parameters were on the left testis.

The production of more than $20 \times 10^{6}$ spermatozoa $\mathrm{ml}^{-1}$ corresponded to normal spermatogenesis (group 1 ; five men) (Table 1). Production of fewer than $20 \times 10^{6}$ spermatozoa $\mathrm{ml}^{-1}$ corresponded to (i) slight hypospermatogenesis (group 2; two men); (ii) marked hypospermatogenesis (group 3; four men); and (iii) maturation arrest (group 4; one man). For azoospermia, testis data corresponded to the various groups 

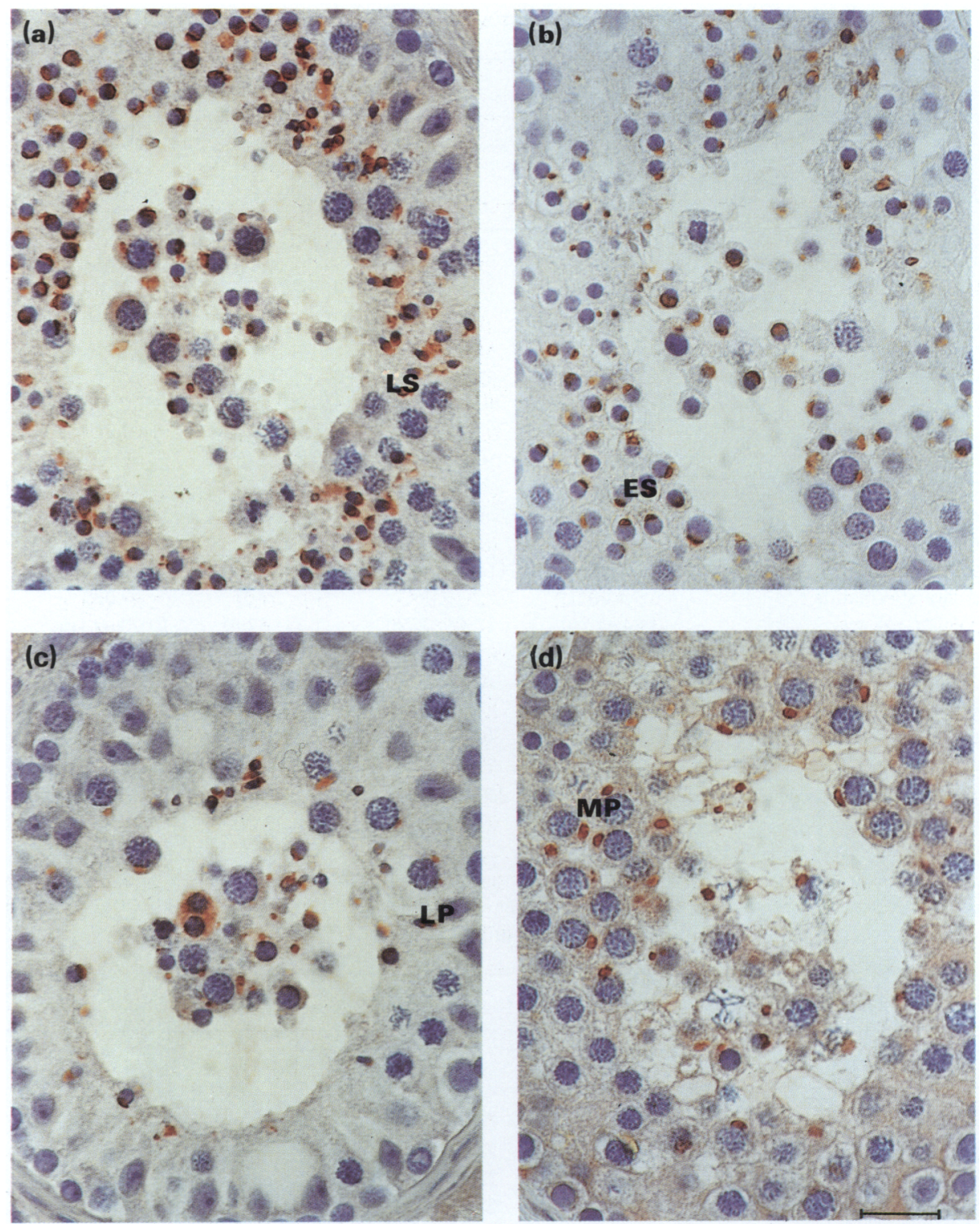

Fig. 2. Monoclonal antibody 4D4 immunolabelling of human seminiferous epithelium (Bouin's fixed, paraffin-embedded testicular biopsies labelled by the avidin-biotin-immunoperoxidase procedure). Bar represents $20 \mu \mathrm{m}$. (a) Seminiferous tubule from a biopsy of Group 1 (normal spermatogenesis) showing germ cells at various stages of spermatogenesis (LS: late spermatid). (b) Seminiferous tubule from a biopsy of Group 2 (slight hypospermatogenesis) showing fewer pachytene primary spermatocytes and spermatids (ES: early spermatid). (c) Seminiferous tubule from a biopsy of Group 3 (marked hypospermatogenesis) characterized by much fewer germ cells at all stages. Note the high degree of germ cell sloughing (LP: late-pachytene primary spermatocyte). (d) Seminiferous tubule from a biopsy of Group 4 (maturation arrest) showing germ cell differentiation arrest at the mid-pachytene primary spermatocyte step (MP: mid-pachytene primary spermatocyte).

defined in this study including normal spermatogenesis and all were associated with genital tract obstruction, except for the cases exhibiting maturation arrest.

\section{Distribution of sloughed germ cells}

The cell types exhibiting significant variation between groups (as estimated by Kruskal-Wallis test) were almost identical to those identified in the seminiferous epithelium, except for sloughed late-pachytene primary spermatocytes (Table 4). In contrast to the results obtained at the epithelium level, the medians of primary spermatocytes in the metaphase, anaphase and telophase stages and of secondary spermatocytes were greater in groups 3 and 4 . For the four testicular biopsy groups, the number of each type of germ cell in the lumen was poorly correlated with that of cells present in the epithelium, 
Table 4. Cells in the lumen of the seminiferous tubules of men

\begin{tabular}{|c|c|c|c|c|c|}
\hline & \multicolumn{5}{|c|}{ Spermatogenesis classification } \\
\hline & \multicolumn{3}{|c|}{ Hypospermatogenesis } & \multirow{2}{*}{$\begin{array}{c}\text { Maturation } \\
\text { arrest }\end{array}$} & \multirow[b]{2}{*}{$P$} \\
\hline & Normal & Slight & Marked & & \\
\hline Mid-pachytene & $\begin{array}{c}0.48^{\mathrm{a}} \\
(0.32,0.84)\end{array}$ & $\begin{array}{c}0.78^{\mathrm{a}, \mathrm{b}} \\
(0.36,0.88)\end{array}$ & $\begin{array}{c}0.64^{\mathrm{a}, \mathrm{b}} \\
(0.28,0.96)\end{array}$ & $\begin{array}{c}1.16^{b} \\
(0.56,1.52)\end{array}$ & 0.05 \\
\hline Late-pachytene & $\begin{array}{c}0.20 \\
(0.12,0.24)\end{array}$ & $\begin{array}{c}0.14 \\
(0.12,0.36)\end{array}$ & $\begin{array}{c}0.36 \\
(0.12,0.44)\end{array}$ & $\begin{array}{c}0.14 \\
(0.00,0.20)\end{array}$ & NS \\
\hline Metaphase, anaphase and telophase & $\begin{array}{c}0.01^{\mathrm{a}} \\
(0.00,0.04)\end{array}$ & $\begin{array}{c}0.04^{\mathrm{a}, \mathrm{b}} \\
(0.00,0.04)\end{array}$ & $\begin{array}{c}0.05^{a, b} \\
(0.00,0.08)\end{array}$ & $\begin{array}{c}0.06^{b} \\
(0.00,0.16)\end{array}$ & 0.04 \\
\hline Secondary spermatocytes & $\begin{array}{c}0.01^{\mathrm{a}} \\
(0.00,0.04)\end{array}$ & $\begin{array}{c}0.01^{\mathrm{a}} \\
(0.00,0.04)\end{array}$ & $\begin{array}{c}0.16^{b} \\
(0.00,0.16)\end{array}$ & $\begin{array}{c}0.01^{\mathrm{a}} \\
(0.00,0.04)\end{array}$ & $<0.01$ \\
\hline Early spermatids & $\begin{array}{c}3.44^{\mathrm{a}} \\
(1.48,5.24)\end{array}$ & $\begin{array}{c}3.10^{\mathrm{a}} \\
(1.92,3.80)\end{array}$ & $\begin{array}{c}2.28^{\mathrm{a}} \\
(1.56,3.52)\end{array}$ & $\begin{array}{c}0.14^{\mathrm{b}} \\
(0.00,0.20)\end{array}$ & $<0.01$ \\
\hline Late spermatids & $\begin{array}{c}1.56^{\mathrm{a}} \\
(0.88,2.36)\end{array}$ & $\begin{array}{c}1.20^{a . b} \\
(0.52,1.56)\end{array}$ & $\begin{array}{c}0.56^{\mathrm{b}} \\
(0.44,0.68)\end{array}$ & $\begin{array}{c}0.01^{c} \\
(0.00,0.04)\end{array}$ & $<0.01$ \\
\hline Unlabelled late spermatids & $\begin{array}{c}0.72^{\mathrm{a}} \\
(0.48,1.04)\end{array}$ & $\begin{array}{c}0.50^{a} \\
(0.16,0.56)\end{array}$ & $\begin{array}{c}0.24^{\mathrm{a} b \mathrm{~b}} \\
(0.12,0.52)\end{array}$ & $\begin{array}{c}0.01^{\mathrm{b}} \\
(0.00,0.02)\end{array}$ & $<0.01$ \\
\hline Multinucleate germ cells & $\begin{array}{c}0.04 \\
(0.00,0.04)\end{array}$ & $\begin{array}{c}0.04 \\
(0.04,0.08)\end{array}$ & $\begin{array}{c}0.12 \\
(0.04,0.16)\end{array}$ & $\begin{array}{c}0.00 \\
(0.00,0.00)\end{array}$ & NS \\
\hline Degenerating germ cells & $\begin{array}{c}0.56 \\
(0.12,0.80)\end{array}$ & $\begin{array}{c}0.24 \\
(0.16,0.52)\end{array}$ & $\begin{array}{c}0.40 \\
(0.24,0.48)\end{array}$ & $\begin{array}{c}0.10 \\
(0.00,0.14)\end{array}$ & NS \\
\hline Unlabelled round germ cells & $\begin{array}{c}0.32 \\
(0.08,0.44)\end{array}$ & $\begin{array}{c}0.82 \\
(0.28,1.12)\end{array}$ & $\begin{array}{c}0.80 \\
(0.64,0.80)\end{array}$ & $\begin{array}{c}0.52 \\
(0.16,0.60)\end{array}$ & NS \\
\hline Sertoli cells & $\begin{array}{c}0.01 \\
(0.00,0.04)\end{array}$ & $\begin{array}{c}0.04 \\
(0.00,0.12)\end{array}$ & $\begin{array}{c}0.04 \\
(0.00,0.08)\end{array}$ & $\begin{array}{c}0.01 \\
(0.00,0.04)\end{array}$ & NS \\
\hline
\end{tabular}

Values are medians with $95 \%$ confidence limits. ${ }^{a, b, c}$ Values with different superscripts are significantly different $(P<0.05)$. NS: not significant.

except for late spermatids of group $4(r=0.95)$. The rate of cell sloughing was: group $1(10.01 \%)$; group $2(12.75 \%)$; group 3 (18.50\%); and group $4(20.79 \%)$. In all testicular biopsy groups, the medians of degenerating germ cells $(<0.6)$, unlabelled round germ cells $(<0.8)$ and Sertoli cells $(<0.1)$ were very low and showed no significant differences among groups. There was no difference between testicular biopsies from autopsies and from infertile patients with normal spermatogenesis.

\section{Discussion}

The specific $4 \mathrm{D} 4$ labelling pattern at various stages of spermatogenesis allows the identification of germ cell stages. Identification is particularly clear for mid- and late-pachytene primary spermatocytes, and for secondary spermatocytes and early spermatids, which are difficult to distinguish from conventional techniques (Paniagua et al., 1987; Skakkebaek et al., 1989). Moreover, in disturbed spermatogenesis, germ cells in the first meiotic prophase can show swollen or disorganized chromatin (Holstein et al., 1988). The 4D4 labelling pattern allows their identification at both epithelial and luminal levels, unless cell changes have induced proacrosin alteration.

The study of the testicular biopsies on the basis of discriminative variables obtained from differential germ cell counts and statistical methods have allowed the analysis of spermatogenesis on the basis of individual biopsies rather than on individual patients and, thus studies of unilateral biopsies. There were quantitative differences between the right and the left testes in six men. Nevertheless, bilateral biopsies showed moderate differences - such as normal spermatogenesis and slight hypospermatogenesis, or slight hypospermatogenesis and marked hypospermatogenesis. This result is probably related to regional differences (i.e. vascularization) between the two testes and confirms the importance of performing bilateral testis biopsies (Nistal and Paniagua, 1984; Holstein et al., 1988). In another study, there was no difference in the total number of germ cells between right and left testicular biopsies (Guarch et al., 1992). Such differences between studies confirm the importance of quantitative evaluation.

Slight hypospermatogenesis with about 20 late spermatids per seminiferous tubule section results in the production of more than $10 \times 10^{6}$ spermatozoa ml ${ }^{-1}$ (Silber et al., 1981; Nistal et al., 1987). Since men with $5 \times 10^{6}$ or more spermatozoa $\mathrm{ml}^{-1}$ can be of normal fertility (Jouannet et al., 1988), slight hypospermatogenesis could be considered as being without functional consequences. In five of these cases, genital tract obstruction was present and this is known to affect spermatogenesis (Sigg and Hedinger, 1981; Holstein et al., 1988 ).

Until now it was unclear whether the number of either spermatids or of spermatids and spermatocytes was lower in hypospermatogenesis (Narbaitz et al., 1978; Nistal et al., 1987). The method used in the study reported here shows that the number of both pachytene primary spermatocytes, and early 
and late spermatids have to be considered for the classification of a given biopsy. The data suggest that slight hypospermatogenesis may be due to fewer cells entering meiosis, which may be related to the decreased spermatogonia which is attributed to the spermatogonial stem cells (Nistal et al., 1987). In contrast, marked hypospermatogenesis appears to have, in addition, loss of germ cells during later meiotic steps and spermiogenesis.

The most common form of maturation arrest in humans affects primary spermatocytes (Nistal and Paniagua, 1984; Francavilla $e t$ al., 1989). In the testicular biopsy series studied, the 4D4 labelling revealed that maturation arrest could occur at the level of either mid-pachytene primary spermatocytes or earlier as seen by the absence of 4D4 labelling in the excluded cases. In addition, as some cells escape the blockage, maturation arrest has been considered as a type of hypospermatogenesis (Honoré, 1979), and its existence as a separate entity has been questioned (Guarch et al., 1992). However, in the study reported here, significant differences were found between these two disturbances of spermatogenesis, supporting the notion that these disorders must be of different origin (Nistal and Paniagua, 1984; Skakkebaek et al., 1989).

It is not known whether the frequent presence of immature germ cells in the lumen of seminiferous tubules is due to specimen processing (Honoré, 1979; Pesce, 1987) or is of pathological significance (Cameron et al., 1980; Bairati et al., 1985). Data from the study reported here appear to agree with the second hypothesis. Indeed, the number of sloughed germ cells (of any type) was not proportional to that of germ cells in the epithelium. Moreover, there were more sloughed germ cells in marked hypospermatogenesis and in maturation arrest than in the other testicular biopsy groups.

The 4D4 immunolabelling of testicular biopsies allows the establishment of new characteristics of normal and disturbed human spermatogenesis and the study of germ cell sloughing. The differential $4 \mathrm{D} 4$ labelling patterns at each stage of spermatogenesis should allow an automated analysis of human testicular biopsies and allow a reliable and fast method for evaluating spermatogenesis.

The authors would like to thank G. David (Université Paris XI, France) and R. Paniagua (Universidad de Alcalá de Henares, Spain) for helpful discussion, the Department of Urology and J. C. Soufir (CHU Bicêtre, France) for providing human testicular biopsies, and A. Peláez (Facultad de Medicina, Málaga, Spain) for drawing Figure 1. This work was supported by grants from the Agence Nationale de Valorisation de la Recherche (No x-84-07-039T-029-0) and Bio Merieux, France (No 89606900 ) and by grants to D. Bermúdez from DGICYT (Ministerio de Educación, Madrid, Spain) and Consejería de Educación (Junta de Andalucía, Sevilla, Spain).

\section{References}

Bairati A, DellaMorte Es Pasini M and Vitellano L (1985) The morphology of seminiferous tubules of human testicular biopsies. Analysis of the data obtained with two different techniques Journal of Submicroscopic Cytology 17 $449-457$

Cameron DF, Snydle FE, Ross MH and Dryle DM (1980) Ultrastructural alterations in the adluminal testicular compartment in men with varicocele Fertility and Sterility 33 526-533

Clermont Y (1963) The cycle of the seminiferous epithelium in man American Journal of Anatomy 112 35-51
Colgan TJ, Bedard YC, Strawbridge HTG, Buckspan MB and Klotz PG (1980) Reappraisal of the value of testicular biopsy in the investigation of infertility Fertility and Sterility 33 56-60

Escalier D, Gallo JM, Albert M, Meduri G, Bermúdez D, David G and Schrével J (1991) Human acrosome biogenesis: immunodetection of proacrosin in primary spermatocytes and of its partitioning pattern during meiosis Development $113779-788$

Escalier D, Bermúdez D, Gallo JM, Viellefond A and Schrével J (1992) Cytoplasmic events in human meiotic arrest as revealed by immunolabelling of spermatocyte proacrosin Differentiation 51 233-243

Flörke-Gerloff S, Phi-Van L, Müller-Esterl W, Sheuber HP and Engel W (1983) Acrosin in the spermiohistogenesis of mammals Differentiation 24 250-256

Francavilla S, Martini M, Propenzi G and Cordesch G (1989) Quantitative parameters of seminiferous epithelium in secretory and excretory oligoazoospermia Archives of Andrology 24 277--285

Gallo JM, Escalier D, Grellier P, Precigout E, Albert M, David G and Schrével J (1991) Characterization of a monoclonal antibody to proacrosin and its use in acrosomal status evaluation Joumal of Histochemistry and Cytochemistry 39 273-282

Guarch R, Pesce C, Puras A and Lazaro J (1992) A quantitative approach to the classification of hypospermatogenesis in testicular biopsies for infertility Human Pathology 23 1032-1037

Hand DJ (1981) Discrimination and Classification pp 120-185. Wiley \& Sons, New York

Herr JC, Flickinger C, Homyk M, Klotz K and John E (1990) Biochemical and morphological characterization of the intraacrosomal antigen SP-10 from human sperm Biology of Reproduction 42 18I-193

Hirsch IH and Choi H (1990) Quantitative testicular biopsy in congenital and acquired genital tract obstruction Journal of Urology $143311-312$

Holstein AF and Roosen-Runge EC (1981) Atlas of Human Spermatogenesis pp 64-107. Gross-Verlag, Berlin

Holstein AF, Roosen-Runge EC and Schirren C (1988) Illustrated Pathology of Human Spermatogenesis pp 58-102. Gross-Verlag, Berlin

Honoré LH (1979) Testicular biopsy for infertility: a review of sixty-eight cases with a simplified histologic classification of lesions International Journal of Fertility 24 49-52

Jassim A and Festenstein H (1987) Molecular dissection of human testicular germ cell differentiation with monoclonal antibodies Journal of Reproductive Immunology 12 173-189

Johnson L, Nguyen HB, Petty CS and Neaves WB (1987) Quantification of human spermatogenesis: germ cell degeneration during spermatocytogenesis and meiosis in testes from younger and older adult men Biology of Reproduction 37 739-747

Jones CJP, Benbow EW, Knox WF and Stoddart RW (1988) Method for showing human spermatogenesis using Arachis hypogaea (AHA) lectin Journal of Clinical Pathology 41 1017-1018

Jouannet P, Ducot D, Feneux D and Spira A (1988) Male factors and the likelihood of pregnancy in infertile couples. I. Study of sperm characteristics International Journal of Andrology 11 379-394

Kurpitz M, Mapp P, Lukaszyk A, Ogilvie J, Festenstein H and Sachs J (1988) Characterization of two monoclonal antibodies raised against human testicular cells Andrologia 20 304-310

Kurth BE, Klotz K, Flickinger CJ and Herr JC (1991) Localization of sperm antigen SP-10 during the six stages of the cycle of the seminiferous epithelium in man Biology of Reproduction 44 814-821

Narbaitz R, Tornai G, Jolly EE, Brawin N and Mckay DE (1978) Ultrastructure studies on testicular biopsies from eighteen cases of hypospermatogenesis Fertility and Sterility 30 679-686

Nistal M and Paniagua R (1984) Testicular biopsy: basic testicular lesions. In Testicular and Epididymal Pathology pp 94-107 Eds M Nistal and R Paniagua. Thieme-Stratton, Inc., New York

Nistal M, Codesal J, Santamaria L and Paniagua R (1987) Correlation between spermatozoon numbers in spermiogram and seminiferous epithelium histology in testicular biopsies from subfertile men Fertility and Sterility $\mathbf{4 8}$ 507-509

Paniagua R, Codesal J, NistaI M, Rodriguez MC and Santamaría L (1987) Quantification of cell types throughout the cycle of the human seminiferous epithelium and their DNA content. A new approach to the spermatogonial stem cell in man Anatomy and Embryology 176 225-230

Pesce C (1987) The testicular biopsy in the evaluation of male infertility Seminars in Diagnostic Pathology 4 264-274 
Phi-Van L, Müller-Esterl W, Flörke S, Schmid M and Engel W (1983) Proacrosin and the differentiation of the spermatozoa Biology of Reproduction 29 479-486

Rowley MJ and Heller CG (1971) Quantification of the cells of the seminiferous epithelium of the human testis employing the Sertoli cells as a constant Zeitschrift fur Zellforschung und Mikroskopysche Anatomie 115 461-472

Schultze W and Rehder V (1984) Organization and morphogenesis of the human seminiferous epithelium Cell and Tissue Research 237 395-407

Sigg C and Hedinger C (1981) Quantitative and ultrastructural study of germinal epithelium in testicular biopsies with mixed atrophy Andrologia 13 $412-424$

Silber SJ and Rodriguez-Rigau LJ (1981) Quantitative analysis of testicle biopsy: determination of partial obstruction and prediction of sperm count after surgery for obstruction Fertility and Sterility 36 480-485

Skakkebaek NE, Hammen R, Philip J and Rebbe H (1973) Quantification of human seminiferous epithelium. III. Histological studies in 44 infertile men with normal chromosome complements Acta Pathologica et Microbiologica Scandinavica $8197-111$
Skakkebaek NE, Berthelsen JG and Müller J (1989) Spermatogenesis and the interpretation of the testicular biopsy. In Recent Advances in Andrology Pp 1-12 Ed. G Waites. Serono Symposia Review, 20, series A

Weissbach L and Ibach B (1976) Quantitative parameters for light microscopic assessment of the tubuli seminiferi Fertility and Sterility 27 836-847

Winer BJ (1962) Statistical Principles in Experimental Design pp 514-538. McGraw Hill, New York

Wollina V, Schreiber G, Zollmann C, Hipler C and Günther E (1989) Lectinbinding sites in normal human testis Andrologia 21 127-130

Young FW (1987) Multidimensional Scaling pp 45-158. LEA, New Jersey

Zukerman Z, Rodriguez-Rigau LJ, Weiss DB, Chowdhury AK, Smith KD and Steinberger E (1978) Quantitative analysis of the seminiferous epithelium in human testicular biopsies and the relation of spermatogenesis to sperm density Fertility and Sterility 30 448-455 